\title{
Flavonoids with a-glucosidase inhibitory activities and their contents in the leaves of Morus atropurpurea
}

\author{
Hin-Chu Hong ${ }^{1}$, Song-Lin Li ${ }^{2}$, Xiao-Qi Zhang ${ }^{3}$, Wen-Cai Ye ${ }^{3}$ and Qing-Wen Zhang ${ }^{1 *}$
}

\begin{abstract}
Background: This study aims to isolate the a-glucosidase inhibitory compounds from mulberry leaves (Morus atropurpurea Roxb., Moraceae) and to develop an analytical method for quantification of the compounds.

Methods: Four flavonoids, rutin (1), isoquercetin (2), kaempferol-3-O-rutinoside (3) and astragalin (4), were isolated by column chromatography from mulberry leaf water extracts (MWE). The a-glucosidase inhibitory activities of MWE and the four isolated compounds were evaluated by a microplate-based in vitro assay. The content of the isolated flavonoids in M. atropurpurea leaves purchased from different local herbal stores or collected in different locations was determined by high performance liquid chromatography.

Results: The four flavonoids (1-4) showed a-glucosidase inhibitory activities, with rutin (1) and astragalin (4) showing high a-glucosidase inhibitory activities $\left(\mathrm{IC}_{50}\right.$ values of $13.19 \pm 1.10$ and $15.82 \pm 1.11 \mu \mathrm{M}$, respectively). The total contents of the four flavonoids were different among eight samples examined, ranging from $4.34 \mathrm{mg} / \mathrm{g}$ to $0.53 \mathrm{mg} / \mathrm{g}$.
\end{abstract}

Conclusions: The four flavonoids in M. atropurpurea leaves could inhibit a-glucosidase activity.

\section{Background}

Postprandial hyperglycemia is one of the earliest abnormalities of glucose homoeostasis [1]. The production and absorption of glucose can be decreased through the inhibition of a carbohydrate hydrolyzing enzyme, $\alpha$-glucosidase [2]. Water extracts from some species of mulberry leaves (Moraceae) show potent antihyperglycemic activities via $\alpha$-glucosidase inhibition [3-5]. It was subsequently found that this $\alpha$-glucosidase inhibition was attributed to the actions of iminosugars such as 1-deoxynojirimycin (1-DNJ) and N-methyl-1-deoxynojirimycin (N-methyl-1-DNJ) [6,7]. Flavonoids, which are widely distributed in the plant kingdom, have also been shown to decrease blood glucose levels $[2,8]$.

This study aims to isolate the $\alpha$-glucosidase inhibitory compounds from mulberry leaves (Morus atropurpurea Roxb., Moraceae) and to develop an analytical method for quantification of the compounds. The $\alpha$-glucosidase

\footnotetext{
* Correspondence: qwzhang@umac.mo

${ }^{1}$ State Key Laboratory of Quality Research in Chinese Medicine, Institute of Chinese Medical Sciences, University of Macau, Macao, China

Full list of author information is available at the end of the article
}

inhibitory activity of $M$. atropurpurea leaf water extracts (MWE) was evaluated. Four flavonoids, rutin (1), isoquercetin (2), kaempferol-3-O-rutinoside (3), and astragalin (4), were isolated from M. atropurpurea Roxb. leaves purchased from different local herbal stores or collected in different locations. The content of individual flavonoids in $M$. atropurpurea leaves was determined by high performance liquid chromatography (HPLC).

\section{Methods}

Materials and chemicals

Acetonitrile (HPLC grade) and acetic acid (HPLC grade) were purchased from Merck (Darmstadt, Germany), and methanol (AR grade) was purchased from Kaitong (Tianjin, China). Sodium carbonate was purchased from BDH Laboratory Supplies (Poole, Dorset, UK). $\alpha$-Glucosidase type 1 (EC 3.2.1.200 from Saccharomyces cerevisias) and 4-nitrophenyl $\alpha$-D-glucopyranoside (pNPG) were purchased from Sigma-Aldrich (St. Louis, MO, USA). Ultra-pure water was purified using a Millipore Milli Q-Plus system (Billerica, MA, USA). Reference compounds of rutin (1), isoquercetin (2), kaempferol-3-O-rutinoside (3), astragalin (4) were 
isolated from M. atropurpurea. Silica gel (200-300 mesh) was purchased from Qingdao Haiyang Chemical Co. Ltd. (Qingdao, China). Macroporous absorption resin (D101) was purchased from Haiguang Chemical Industrial Co. (Tianjin, China). Sephadex LH-20 was purchased from GE Healthcare Bio-Sciences AB (Uppsala, Sweden), and the Millex ${ }^{\bullet}$ nylon membrane syringe filter was purchased from Millipore (Billerica, MA, USA).

Samples of $M$. atropurpurea (10 kg of leaves of the sample for separation and $500 \mathrm{~g}$ of each of the samples for analysis) were purchased from local herbal stores or collected arbitrarily in Guangdong Province, China. The botanical origin of the raw materials was authenticated by Professor Guang-Xiong Zhou at the College of Pharmacy, Jinan University, Guangzhou, China by morphological identification [9,10]. Voucher specimens (ICMS20110421) were deposited in the Institute of Chinese Medical Sciences, University of Macau, Macau SAR, China.

\section{Apparatus}

Electrospray injection mass spectrometry (ESI-MS) was performed on an Agilent 1100 LC/MSD Trap Mass Spectrometer (Agilent, USA), and ${ }^{1} \mathrm{H}{ }^{13} \mathrm{C}$ NMR spectra were obtained using a $300 \mathrm{MHz}$ NMR spectrometer (Bruker, Germany). HPLC analyses were performed using an Agilent 1200 HPLC (Agilent, USA) system. Extraction was carried out using the Syncore Polyvap Analyst and Reactor (BUCHI, Switzerland). The absorbance readings in enzymatic assays were recorded by a SpectraMax ${ }^{\circledR}$ M5 multi-mode microplate reader (Molecular Devices, USA).

\section{Isolation}

Nine $\mathrm{kg}$ of air-dried $M$. atropurpurea leaves were extracted with boiling water $(3 \times 20 \mathrm{~L}, 1 \mathrm{~h}$ each). The extract was filtered and subjected to a D101 macroporous adsorption resin column, then eluted with $\mathrm{H}_{2} \mathrm{O}, 30 \% \mathrm{EtOH}$, $40 \% \mathrm{EtOH}, 60 \% \mathrm{EtOH}$ and $100 \% \mathrm{EtOH}$ (v/v, $\left.\mathrm{H}_{2} \mathrm{O}-\mathrm{EtOH}\right)$ sequentially. The $40 \% \mathrm{EtOH}$ fraction was concentrated to dryness and then suspended in $\mathrm{H}_{2} \mathrm{O}$. The water suspension was partitioned with EtOAc $\left(\mathrm{v} / \mathrm{v}, \mathrm{H}_{2} \mathrm{O}-\right.$ EtOAc $\left.=1: 1\right)$ 3 times to obtain EtOAc fractions, while the remaining $\mathrm{H}_{2} \mathrm{O}$ fraction was partitioned with $\mathrm{BuOH}\left(\mathrm{v} / \mathrm{v}, \mathrm{H}_{2} \mathrm{O}-\right.$ $\mathrm{BuOH}=2: 1$ ) three more times to obtain $\mathrm{BuOH}$ fractions. The EtOAc fraction was concentrated to dryness and subjected to silica gel chromatography column, using $\mathrm{CHCl}_{3}-\mathrm{MeOH}-\mathrm{H}_{2} \mathrm{O}$ (from $\mathrm{CHCl}_{3}-\mathrm{MeOH}-\mathrm{H}_{2} \mathrm{O}=20: 1: 0$ to $\left.\mathrm{CHCl}_{3}-\mathrm{MeOH}-\mathrm{H}_{2} \mathrm{O}=70: 30: 5\right)$ as eluent to afford 40 fractions (E1-E40). Fractions E25-E29 were further separated by a Sephadex LH-20 column eluted with methanol to afford flavonoid 4 (20 mg). Fractions E30-E40 were further separated by a Sephadex LH-20 column eluted with methanol to afford 20 fractions (Ea1-Ea20). Fractions Ea1-Ea20 were further purified by preparative HPLC $(\mathrm{C} 18$, column flow rate $=10 \mathrm{~mL} / \mathrm{min} 45 \% \mathrm{MeOH}$
$30 \mathrm{~min})$ to afford flavonoid $2(15 \mathrm{mg})$. The $\mathrm{BuOH}$ fractions were concentrated to dryness and subjected to a silica gel column using $\mathrm{CHCl}_{3}-\mathrm{MeOH}$ as eluent to afford 24 fractions (B1-B24). Fractions B17-B24 were further purified by a Sephadex LH-20 column eluted with methanol to afford flavonoid 3 (30 mg). Fractions B8-16 were further purified by a Sephadex LH-20 column eluted with methanol to afford flavonoid 1 (15 mg).

\section{a-glucosidase assay}

The yeast $\alpha$-glucosidase inhibitory activities of the four flavonoids were determined by a microplate-based method [11] with a slight modification. In the sample group, a total of $80 \mu \mathrm{L}$ of reaction mixture contained $20 \mu \mathrm{L}$ each of $100 \mathrm{mM}$ phosphate buffer (pH 6.8), $2.5 \mathrm{mM}$ pNPG in the buffer, experimental drug and $2.4 \mathrm{U} / \mathrm{mL} \alpha$-glucosidase. After incubation of the 96 -well plates at $37^{\circ} \mathrm{C}$ for $30 \mathrm{~min}$, $80 \mu \mathrm{L}$ of $0.2 \mathrm{~mol} / \mathrm{L}$ sodium carbonate solution was added to each well to stop the reaction. The 4-nitrophenol absorption was measured at $405 \mathrm{~nm}$. In the control group, the composition of the reaction mixture was the same as in sample group except that solvent was used instead of the experimental drug. In the sample and control blank groups, the composition was same as in the sample group except that $\alpha$-glucosidase was used instead with buffer. The inhibitory activity was calculated using the following formula:

$$
\text { Inhibitory activity }(\%)=1-\left(A_{S}-A_{S B}\right) /\left(A_{C}-A_{C B}\right) \times 100
$$

where $A_{S}, A_{S B}, A_{C}$, and $A_{C B}$ are the absorbances of sample, sample blank, control, and control blank, respectively.

\section{Sample preparation}

The leaves of $M$. atropurpurea were refluxed on a Syncore Polyvap Analyst Reactor under optimized conditions. Dried powder of $M$. atropurpurea leaves $(0.4 \mathrm{~g})$ was refluxed $\left(100^{\circ} \mathrm{C}\right)$ in $20 \mathrm{~mL}$ of methanol for $1 \mathrm{~h}$. After extraction, solvent was added to the extraction vessel until the final weight equal to the starting weight to counter solvent loss. The extract was thoroughly mixed on a vortex mixer, and filtered through a $0.45 \mu \mathrm{m}$ syringe filter prior to HPLC injection.

\section{Optimization of the sample preparation conditions}

A single factor test was performed by changing one factor, fixing other factors to optimize the sample preparation conditions for the analysis. Five factors, including temperature, extraction time, particle size of raw materials (RM), raw material to solvent ratio (RMTSR), and extraction cycle were examined. For RMTSR, the RMTSR was changed from 1:20 (g:mL) to 1:150 (g:mL), while other factors were set as follows: extraction time $1 \mathrm{~h}$, 


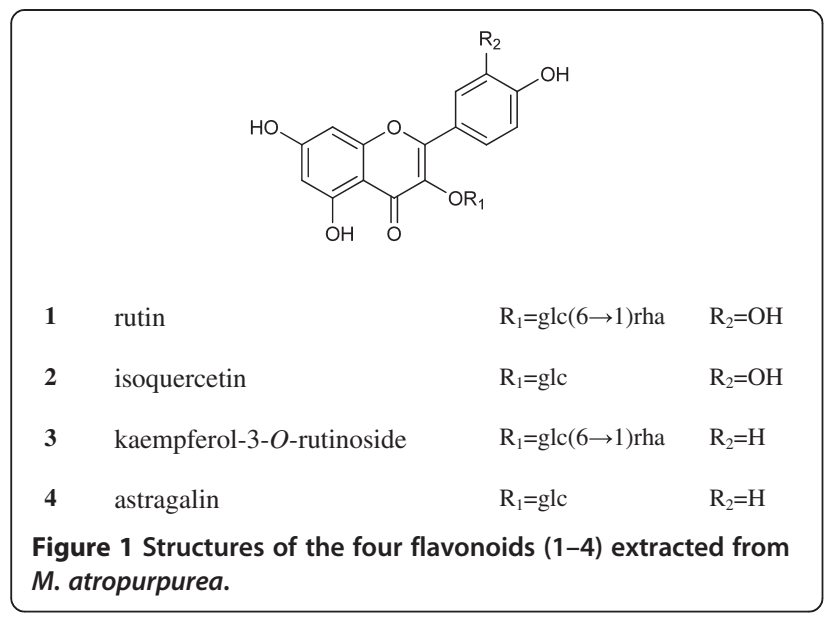

extraction temperature $100^{\circ} \mathrm{C}$, and particle size between 124 and $150 \mu \mathrm{m}$. The temperature was changed from 70 to $100^{\circ} \mathrm{C}$, while other factors were set as follows: extraction time $1 \mathrm{~h}$, RMTSR of 1:100, and particle size between 124 and $150 \mu \mathrm{m}$. The extraction time was changed from $30 \mathrm{~min}$ to $2 \mathrm{~h}$, while other factors were set as follows: RMTSR of $1: 100$, extraction temperature $100^{\circ} \mathrm{C}$, and particle size between 124 and $150 \mu \mathrm{m}$. The particle size of RM was changed from less than $420 \mu \mathrm{m}$ to between 124 and $150 \mu \mathrm{m}$, while other factors were set as follows: extraction time $1 \mathrm{~h}$, extraction temperature $100^{\circ} \mathrm{C}$, and RMTSR of $1: 100$. For optimization of the extraction cycle, the RM was extracted in 1-3 cycles, while other factors were set as follows: extraction time $1 \mathrm{~h}$, extraction temperature $100^{\circ} \mathrm{C}$, RMTSR of 1:100 and particle size between 124 and $150 \mu \mathrm{m}$. The yield of the four analytes was the criterion for the optimization procedures.

\section{Chromatographic conditions}

All experiments were conducted with an Agilent 1200 HPLC system. The mobile phase consisted of water with $0.5 \%$ acetic acid (A) and acetonitrile (B). The gradient programs were as follows: 0-25 $\mathrm{min}, 18-19 \% \mathrm{~B}$; $25-30 \mathrm{~min}$,

Table 1 Inhibitory activities of the four flavonoids against a-glucosidase

\begin{tabular}{lll}
\hline Samples & $\mathbf{I C}_{\mathbf{5 0}}, \boldsymbol{\mu M}$ & $\mathbf{I C}_{\mathbf{5 0}}, \boldsymbol{\mu \mathbf { g }} \mathbf{\mathbf { m L }}$ \\
\hline Acarbose & $780.2 \pm 1.04$ & $503.7 \pm 0.67$ \\
$\mathbf{1}$ & $13.19 \pm 1.10$ & $8.05 \pm 0.67$ \\
$\mathbf{2}$ & $116.7 \pm 1.17$ & $54.19 \pm 0.54$ \\
$\mathbf{3}$ & $365.4 \pm 1.05$ & $217.24 \pm 0.62$ \\
$\mathbf{4}$ & $15.82 \pm 1.11$ & $7.09 \pm 0.28$ \\
WME & - & $27.05 \pm 0.50$ \\
\hline
\end{tabular}

Data are presented as means \pm SD of three measurements $(n=3)$.

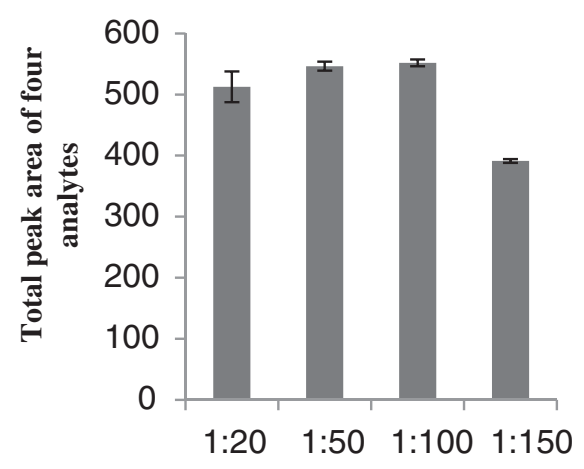

Ratio of raw material to solvent
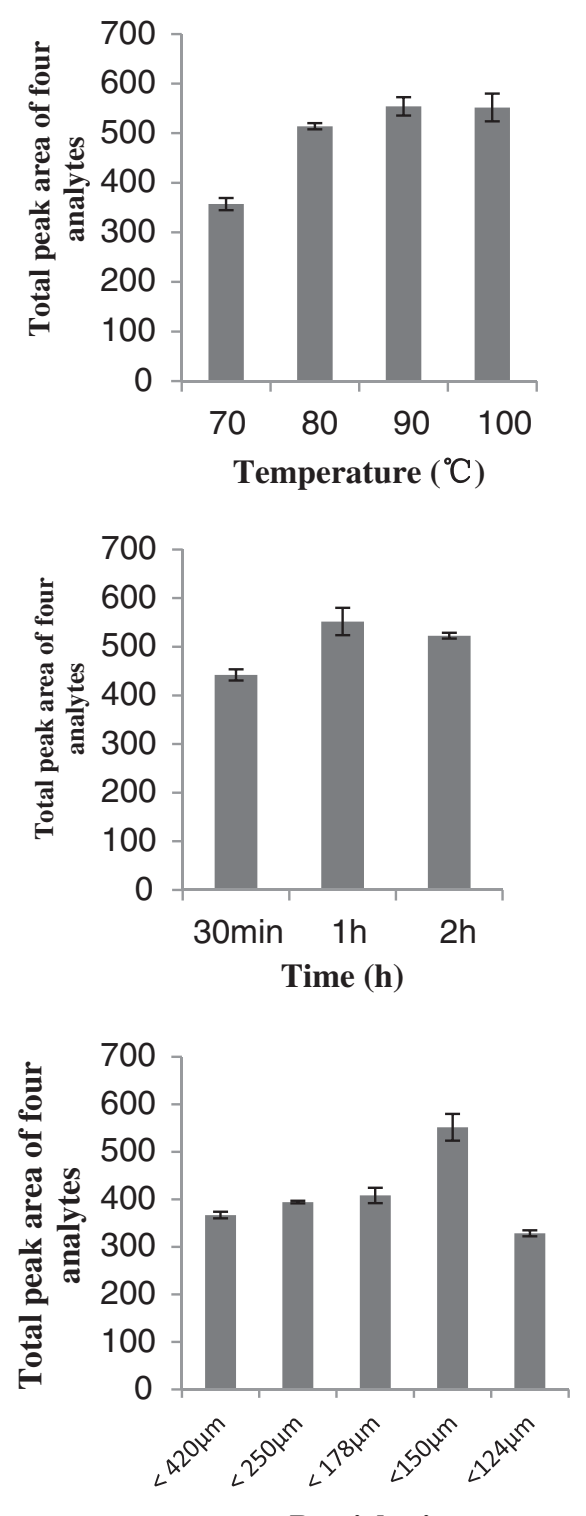

Particle size

Figure 2 Optimization of sample preparation conditions. 
$100 \%$ B. The chromatographic separation was using a Cosmosil $5 \mathrm{C}_{18}$-MS-II $(4.6 \times 250 \mathrm{~mm}, 5 \mu \mathrm{m})$ column with a flow rate of $1 \mathrm{~mL} / \mathrm{min}$. The column temperature was maintained at $30^{\circ} \mathrm{C}$. All analytes were monitored at $350 \mathrm{~nm}$.

\section{Calibration curves}

Stock standard solutions of four flavonoids were prepared in methanol and diluted to different concentrations to build calibration curves. The calibration curves were constructed by plotting the peak areas versus the concentrations of each analyte.

\section{Precision test}

Intra-day and inter-day variations were used to determine the precision of the developed method. The intra-day precision or inter-day precision was determined by analyzing replicated samples (MA06) within 1 day or within 3 consecutive days, respectively.

\section{Stability test}

Sample MA06 was analyzed using the developed method to verify the stability of the samples. The stability test was carried out by analyzing the sample at 0,2 , $4,8,12,24$, and $48 \mathrm{~h}$, and the relative standard deviations (RSDs) of peak areas at different times were calculated.

\section{Accuracy test}

The accuracy of the developed method was evaluated by spike recovery. Flavonoids 1, 2, 3, and $\mathbf{4}$ were added into $0.2 \mathrm{~g}$ of sample MA06. Then, the mixtures were
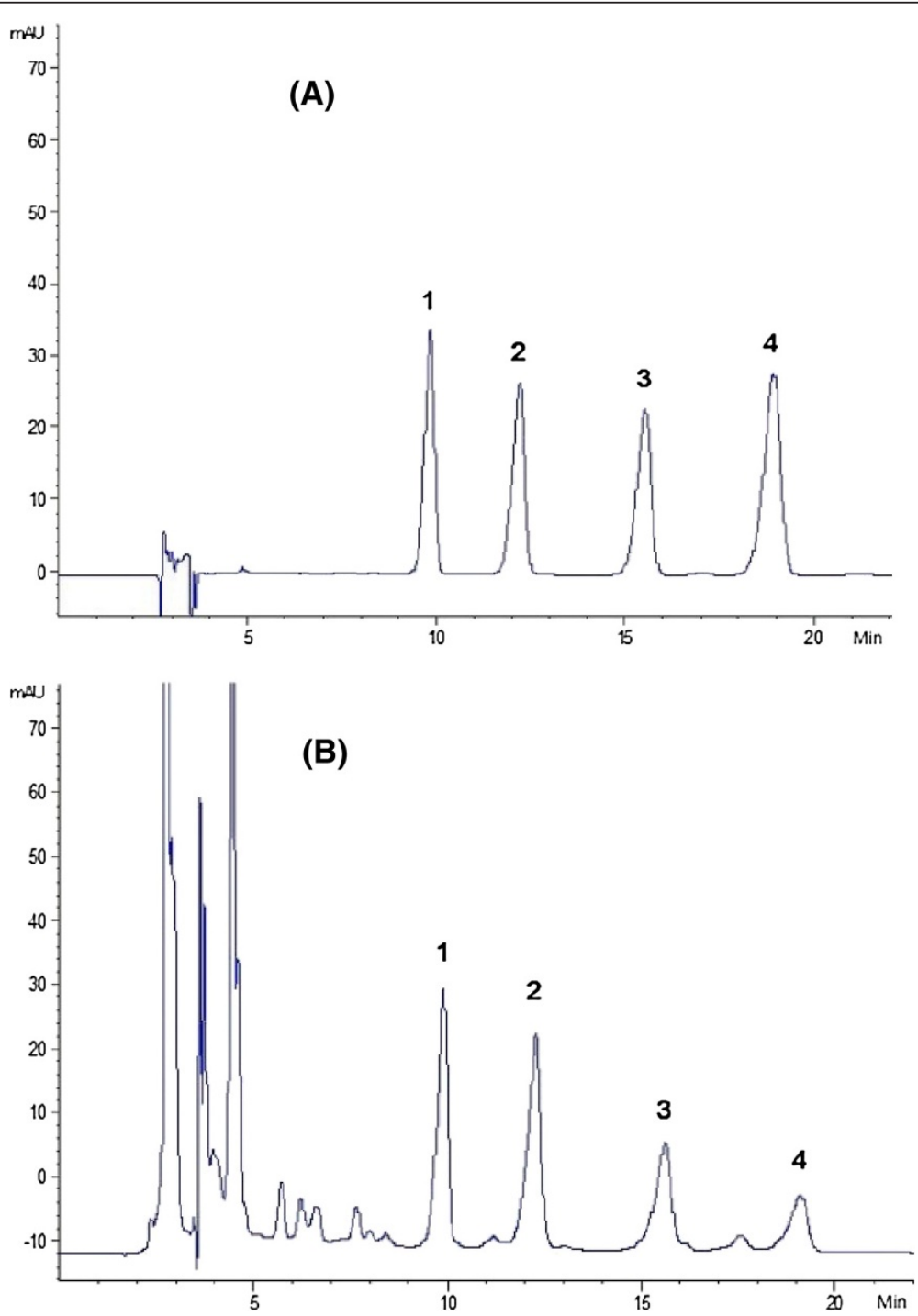

Figure 3 HPLC chromatograms of $\boldsymbol{M}$. atropurpurea leaves. (A) Mixed reference compounds 1: rutin; 2: isoquercetin; 3: kaempferol-3-O-rutinoside; 4: astragalin. (B) Extract of sample MA07. 
Table 2 Calibration curves, LODs, and LOQs for the four flavonoids (1-4)

\begin{tabular}{|c|c|c|c|c|c|c|}
\hline Flavonoids & Calibration curve $^{a}$ & $R^{2}$ & $\mathbf{P}$ & Test range $(\mu \mathrm{g} / \mathrm{mL})$ & $\operatorname{LOD}^{\mathrm{b}}(\mathrm{ng})$ & $\operatorname{LOQ}^{c}(\mathrm{ng})$ \\
\hline 1 & $y=20.981 x-29.365$ & 0.9997 & $<0.001$ & $0.98-500.00$ & 0.49 & 1.64 \\
\hline 2 & $y=32.967 x+16.675$ & 0.9995 & $<0.001$ & $1.26-80.60$ & 0.73 & 2.42 \\
\hline 3 & $y=22.738 x+6.6695$ & 0.9994 & $<0.001$ & $0.20-100.00$ & 1.32 & 4.39 \\
\hline 4 & $y=33.411 x+10.376$ & 0.9992 & $<0.001$ & $0.20-100.00$ & 1.20 & 3.99 \\
\hline
\end{tabular}

${ }^{a} y=$ peak area and $x=$ concentration $(\mu \mathrm{g} / \mathrm{mL})$.

${ }^{b}$ Limit of detection $(\mathrm{S} / \mathrm{N}=3)$.

'Limit of quantification $(\mathrm{S} / \mathrm{N}=10)$.

extracted and analyzed. The spiked recovery was calculated as follows:

$$
\begin{aligned}
\text { Recovery }(\%)= & (\text { amount found-amount original }) \\
& \div \text { amount spiked } \times 100 \%
\end{aligned}
$$

\section{Statistical analysis}

The results are reported as the means \pm standard derivations (SD) of at least three measurements. Significant variables were assessed using the $t$ test, subjecting results to a simple linear regression in Excel (Microsoft, Redmond, WA, USA). Results with $P$ values less than 0.05 were considered to be significant.

\section{Results and discussion}

\section{Structural determination}

Four flavonoids isolated from the $M$. atropurpurea leaves were identified as rutin (1), isoquercetin (2), kaempferol3-O-rutinoside (3), and astragalin (4) (shown in Figure 1) by comparing the MS and NMR data with the literature [10]. The ${ }^{1} \mathrm{H}$ NMR spectra revealed that their purities were all above 98\%, which was also confirmed by HPLC.

\section{a-glucosidase assay}

The $\alpha$-glucosidase assay used acarbose as a positive control with a $50 \%$ inhibitory concentration $\left(\mathrm{IC}_{50}\right)$ of $780.2 \pm 1.04 \mu \mathrm{M}$. As shown in Table 1, all of the tested flavonoids inhibited yeast $\alpha$-glucosidase in a dose-dependent manner. The dose-dependent manner was determined by the dose-inhibition relationship experiment. A series sample concentration was tested to determine the $\mathrm{IC}_{50}$.

Table 3 Variations in intraday and interday precision of HPLC methods for the determination of the four

\begin{tabular}{|c|c|c|c|c|}
\hline \multirow[t]{2}{*}{ Flavonoids } & \multicolumn{2}{|c|}{ Intraday precision $(n=3)$} & \multicolumn{2}{|c|}{ Interday precision $(n=6)$} \\
\hline & Content (mg/g) & $\mathrm{RSD}^{\mathrm{a}}(\%)$ & Content (mg/g) & $\operatorname{RSD}^{a}(\%)$ \\
\hline 1 & $0.81 \pm 0.01$ & 1.32 & $0.75 \pm 0.04$ & 4.73 \\
\hline 2 & $0.53 \pm 0.02$ & 2.90 & $0.52 \pm 0.01$ & 2.16 \\
\hline 3 & $0.42 \pm 0.02$ & 2.60 & $0.37 \pm 0.02$ & 4.88 \\
\hline 4 & $0.25 \pm 0.01$ & 2.83 & $0.23 \pm 0.01$ & 4.81 \\
\hline
\end{tabular}
flavonoids (1-4)

${ }^{\mathrm{a}} \mathrm{RSD}(\%)=100 \times \mathrm{SD} /$ mean .
The $\mathrm{IC}_{50}$ for flavonoids $\mathbf{1}-\mathbf{4}$ were determined to be $13.19 \pm$ $1.10,116.7 \pm 1.17,365.4 \pm 1.05$ and $15.82 \pm 1.11 \mu \mathrm{M}$, respectively. The $\mathrm{IC}_{50}$ for MWE was $27.05 \pm 1.04 \mu \mathrm{g} / \mathrm{mL}$.

\section{Optimization of the sample preparation conditions}

As shown in Figure 2, the effects of the raw material to solvent ratio (RMTSR), temperature, extraction time, and extraction cycle were investigated. The yield of four analytes increased with RMTSR until a ratio of 1:100. The maximum extraction yield was obtained by the RMTSR of 1:100; nevertheless, there was no significant difference between 1:50 and 1:100. The yield of the four analytes increased with temperature from 70 to $90^{\circ} \mathrm{C}$. The maximum extraction yield was obtained at $100^{\circ} \mathrm{C}$; nevertheless, there was no significant difference between 90 and $100^{\circ} \mathrm{C}$. The maximum extraction yield was obtained at $1 \mathrm{~h}$, suggesting that $1 \mathrm{~h}$ is long enough for complete extraction of the analytes. The yield of the four analytes increased with decreasing particle sizes until the sizes were between 124 and $150 \mu \mathrm{m}$. The maximum extraction yield was obtained with particle sizes between 124 and $150 \mu \mathrm{m}$. The extraction rate of the second extraction

Table 4 Accuracy of the HPLC method for the determination of the four flavonoids (1-4)

\begin{tabular}{cccccc}
\hline Flavonoids & $\begin{array}{c}\text { Original } \\
(\mathbf{m g})\end{array}$ & $\begin{array}{c}\text { Spiked } \\
(\mathbf{m g})\end{array}$ & $\begin{array}{c}\text { Found } \\
(\mathbf{m g})\end{array}$ & $\begin{array}{c}\text { Recovery }^{\mathbf{a}} \\
(\mathbf{\%})\end{array}$ & $\begin{array}{c}\mathrm{RSD}^{\mathbf{b}} \\
(\mathbf{\%})\end{array}$ \\
\hline \multirow{2}{*}{$\mathbf{1}$} & 0.14 & 0.13 & 0.27 & 97.8 & 1.99 \\
& & 0.15 & 0.29 & 96.0 & 0.38 \\
& & 0.18 & 0.32 & 100.1 & 2.55 \\
$\mathbf{2}$ & 0.13 & 0.11 & 0.24 & 102.2 & 2.06 \\
& & 0.13 & 0.27 & 103.5 & 3.49 \\
& & 0.07 & 0.29 & 104.0 & 5.51 \\
$\mathbf{3}$ & 0.08 & 0.09 & 0.16 & 104.6 & 2.56 \\
& & 0.10 & 0.19 & 101.9 & 0.96 \\
& & 0.04 & 0.09 & 97.4 & 3.62 \\
$\mathbf{4}$ & 0.05 & 0.05 & 0.10 & 104.6 & 0.65 \\
& & 0.06 & 0.11 & 97.4 & 3.20 \\
\hline
\end{tabular}

${ }^{a}$ Recovery (\%) $=100 \times$ (amount found - original amount) / amount spiked. ${ }^{\mathrm{b}} \mathrm{RSD}(\%)=100 \times \mathrm{SD} /$ mean. 
Table 5 Content of the four flavonoids (1-4) in M. atropurpurea leaves from different locations $(\mathrm{mg} / \mathrm{g})(\mathrm{n}=3)$

\begin{tabular}{|c|c|c|c|c|c|c|}
\hline \multirow[t]{2}{*}{ No. } & \multirow[t]{2}{*}{ Location } & \multicolumn{5}{|c|}{ Flavonoids } \\
\hline & & 1 & 2 & 3 & 4 & Total \\
\hline MA01 & Chaoshan, Guangdong & $0.38 \pm 0.01$ & $0.33 \pm 0.00$ & $0.18 \pm 0.01$ & $0.16 \pm 0.00$ & $1.04 \pm 0.02$ \\
\hline MA02 & Qingping, Guangdong & $0.51 \pm 0.02$ & $0.18 \pm 0.01$ & $0.29 \pm 0.01$ & $0.06 \pm 0.00$ & $1.04 \pm 0.04$ \\
\hline MA03 & Zhanjiang, Guangdong & $0.32 \pm 0.03$ & $0.34 \pm 0.02$ & $N D^{a}$ & $0.17 \pm 0.01$ & $0.83 \pm 0.06$ \\
\hline MA04 & Zhixing, Guangdong & $0.86 \pm 0.03$ & $0.46 \pm 0.01$ & $0.36 \pm 0.01$ & $0.13 \pm 0.00$ & $1.80 \pm 0.04$ \\
\hline MA05 & Caizhilin, Guangdong & $0.86 \pm 0.02$ & $0.67 \pm 0.02$ & $0.34 \pm 0.00$ & $0.28 \pm 0.01$ & $2.12 \pm 0.05$ \\
\hline MA06 & Puning, Guangdong & $0.72 \pm 0.00$ & $0.53 \pm 0.02$ & $0.42 \pm 0.00$ & $0.25 \pm 0.00$ & $1.92 \pm 0.02$ \\
\hline MA07 & Qingping, Guangdong & $1.85 \pm 0.04$ & $1.11 \pm 0.02$ & $0.95 \pm 0.04$ & $0.40 \pm 0.02$ & $4.31 \pm 0.11$ \\
\hline MA08 & Zhanjiang, Guangdong & $0.33 \pm 0.01$ & $0.11 \pm 0.01$ & $0.17 \pm 0.01$ & $0.06 \pm 0.00$ & $0.67 \pm 0.04$ \\
\hline
\end{tabular}

${ }^{\mathrm{a} N D:}$ not detected

was less than $5 \%$ of that of the first extraction, indicating that one extraction cycle was enough for complete extraction.

The results of the single factor test indicated that the extraction conditions could be optimized as follows: RMTSR, 1:100; temperature, $100^{\circ} \mathrm{C}$; extraction time, $1 \mathrm{~h}$; particle size of RM, between 124 and $150 \mu \mathrm{m}$; extraction cycles, 1.

\section{HPLC method development}

A series of mobile phases and elution programs were tested to obtain the baseline separation. All four analytes were eluted with baseline separation on the Cosmosil $5 \mathrm{C}_{18}$-MS-II $(4.6 \times 250 \mathrm{~mm}, 5 \mu \mathrm{m})$ column (Shown in Figure 3).

\section{HPLC method validation}

The method was validated by linearity, the limit of detection (LOD) and quantification (LOQ), precision, stability and accuracy.

\section{Calibration curves, LODs and LOQs}

The calibration curves are summarized in Table 2. All calibration curves showed good linear regressions $\left(R^{2}>0.9992\right)$; $[\mathrm{P}<0.001]$ within the testing range. The LODs and LOQs were less than 0.49 and $1.64 \mathrm{ng}$, respectively.

\section{Precision test}

As shown in Table 3, the RSD values for overall intra-day and inter-day precision were less than 2.90 and $4.88 \%$, for all analytes, suggesting that the developed method was precise enough for determining these flavonoids.

\section{Stability test}

The overall RSDs of peak areas at different times were less than $4.20 \%$, indicating that the sample was stable for at least $24 \mathrm{~h}$.

\section{Accuracy test}

As shown in Table 4, the recoveries of flavonoids 1, 2, 3 and 4 were 97.8-100.1, 102.2-104.0, 96.1-104.6, and 97.4-104.6\% ( $n=3)$, respectively, and the RSDs were less than $5.51 \%$, indicating that the developed method was accurate for determining these four flavonoids.

\section{Quantitative analysis}

The results of quantitative analysis results of eight batches of $M$. atropurpurea are shown in Table 5. The content of these four flavonoids were different from one batch to another, ranging from 4.31 to $0.67 \mathrm{mg} / \mathrm{g}$, indicating the diverse quality of commercial $M$. atropurpurea. Raw materials of $M$. atropurpurea should be collected at a fixed location that enables the assurance of quality consistency, and consequently, consistency of efficacy of this herb.. The content of rutin (1) was highest in MA07, and lowest in MA03, while the content of isoquercetin (2) was highest in MA07, but lowest in MA08. The contents of kaempferol3-O-rutinoside (3) and astragalin (4) were highest in MA07, but lowest in MA08.

\section{Conclusion}

The four flavonoids in $M$. atropurpurea leaves could inhibit $\alpha$-glucosidase activity.

\footnotetext{
Abbreviations

1-DNJ: 1-deoxynojirimycin; N-methyl-1-DNJ: N-methyl-1-deoxynojirimycin; HPLC: High performance liquid chromatography; MWE: Mulberry leaf water extract; ESI-MS: Electric-spray ionization coupled with mass spectrometry; NMR: Nuclear magnetic resonance; pNPG: 4-nitrophenyl a-D-glucopyranoside; RM: Raw materials; RMTSR: Raw material to solvent ratio; LOD: Limit of detection; LOQ: Limit of quantification; RSD: Relative standard deviation.
}

\section{Competing interests}

The authors declare that they have no competing interests.

\section{Authors' contributions}

QWZ and WCY conceived and designed this study. HCH performed the experiments. XQZ collected the materials. $\mathrm{HCH}$, SLL and QWZ wrote the manuscript. All authors read and approved the final version of the manuscript. 


\section{Acknowledgments}

We are grateful to Mr. Leon Lai for his technical assistance. This research is supported by grants from the Macao Science and Technology Development Fund (013/2008/A1), the University of Macau (MYRG191-(Y1-L3)-ICMS11-ZQW), and the Ministry of Science and Technology of China (2013DFM30080 and 2013BAl11B05)

\section{Author details}

${ }^{1}$ State Key Laboratory of Quality Research in Chinese Medicine, Institute of Chinese Medical Sciences, University of Macau, Macao, China. ${ }^{2}$ Department of Pharmaceutical Analysis and Metabolomics, Jiangsu Province Academy of Traditional Chinese Medicine, Nanjing 210028, China. ${ }^{3}$ Institute of Traditional Chinese Medicine and Natural Products, Jinan University, Guangzhou 510632, China.

Received: 18 January 2013 Accepted: 18 August 2013

Published: 14 October 2013

\section{References}

1. WHO: Traditional medicine strategy 2002-2005. Geneva: WHO Publications; 2002.

2. Manaharan T, Appleton D, Cheng HM, Palanisamy UD: Flavonoids isolated from syzygium aqueum leaf extract as potential antihyperglycaemic agents. Food Chem 2012, 132:1802-1807.

3. Kim GN, Kwon YI, Jang HD: Mulberry leaf extract reduces postprandial hyperglycemia with Few side effects by inhibiting alpha-glucosidase in normal rats. J Med Food 2011, 14:712-717.

4. Yatsunami K, Saito Y, Fukuda E, Onodera S, Oshigane K: alpha-glucosidase inhibitory activity in leaves of some mulberry varieties. Food Sci Technol Res 2003, 9:392-394

5. Naowaboot J, Pannangpetch P, Kukongviriyapan V, Kongyingyoes B, Kukongviriyapan U: Antihyperglycemic, antioxidant and antiglycation activities of mulberry leaf extract in Streptozotocin-induced chronic diabetic rats. Plant Food Hum Nutr 2009, 64:116-121.

6. Kwon HJ, Chung JY, Kim JY, Kwon O: Comparison of 1-deoxynojirimycin and aqueous mulberry leaf extract with emphasis on postprandial hypoglycemic effects: in vivo and in vitro studies. J Agr Food Chem 2011, 59:3014-3019

7. Yatsunami K, Ichida M, Onodera S: The relationship between 1-deoxynojirimycin content and alpha-glucosidase inhibitory activity in leaves of 276 mulberry cultivars (Morus spp.) in Kyoto, Japan. J Nat Med 2008, 62:63-66.

8. Yang ZZ, Wang YC, Wang Y, Zhang YF: Bioassay-guided screening and isolation of alpha-glucosidase and tyrosinase inhibitors from leaves of Morus alba. Food Chem 2012, 131:617-625.

9. Zhang T, Deng W, Xie T, Hu X, Ye C: Analysis on the correlation of morphological character of mulberry. Guang Dong Can Ye 2010, 44:30-37.

10. Chu Y, Yu M: Study on the ecological distribution of morus germplasm resources in Yunnan province. Can Ye Ke Xue 2012, 25:1-7.

11. Li T, Zhang XD, Song YW, Liu JW: A mircroplate-based screening method for alpha-glucosidase inhibitors. Zhong Guo Lin Chuang Yao Li Xue Yu Zhi Liao Xue 2005, 10:1128-1134.

doi:10.1186/1749-8546-8-19

Cite this article as: Hong et al:: Flavonoids with a-glucosidase inhibitory activities and their contents in the leaves of Morus atropurpurea. Chinese Medicine 2013 8:19.

\section{Submit your next manuscript to BioMed Central and take full advantage of:}

- Convenient online submission

- Thorough peer review

- No space constraints or color figure charges

- Immediate publication on acceptance

- Inclusion in PubMed, CAS, Scopus and Google Scholar

- Research which is freely available for redistribution

Submit your manuscript at www.biomedcentral.com/submit 